\title{
Physical and Hydraulic Properties of Baked Ceramic Aggregates Used for Plant Growth Medium
}

\author{
Susan L. Steinberg \\ Universities Space Research Association, Mail Code EC3, NASA/JSC, Houston, TX 77058 \\ Gerard J. Kluitenberg \\ Department of Agronomy, Kansas State University, Manhattan, KS 66506 \\ Scott B. Jones \\ Department of Plants, Soils and Biometeorology, Utah State University, Logan UT 84322
}

Nihad E. Daidzic

National Center for Space Exploration Research, NASA/GLENN, Cleveland, OH 44135

Lakshmi N. Reddi and Ming Xiao

Department of Civil Engineering, Kansas State University, Manhattan, KS 66506

Markus Tuller

Soils and Land Resources Division, University of Idaho, Moscow, ID 83844

Rebecca M. Newman

Department of Agronomy, Kansas State University, Manhattan, KS 66506

Dani Or

Department Civil and Environmental Engineering, University of Connecticut, Storrs, CT 06269

J. Iwan D. Alexander

Mechanical and Aerospace Engineering, Case Western Reserve University, Cleveland, OH 44106

\begin{abstract}
AdDitional INDEX wORDS. bulk density, porosity, pore size distribution, water content, water retention, hydraulic conductivity, fritted clay, arcillite

ABstract. Baked ceramic aggregates (fritted clay, arcillite) have been used for plant research both on the ground and in microgravity. Optimal control of water and air within the root zone in any gravity environment depends on physical and hydraulic properties of the aggregate, which were evaluated for $0.25-1-\mathrm{mm}$ and 1-2-mm particle size distributions. The maximum bulk densities obtained by any packing technique were 0.68 and $0.64 \mathrm{~g} \cdot \mathrm{cm}^{-3}$ for $0.25-1-\mathrm{mm}$ and 1-2-mm particles, respectively. Wettable porosity obtained by infiltration with water was $\approx 65 \%$, substantially lower than total porosity of $\approx 74 \%$. Aggregate of both particle sizes exhibited a bimodal pore size distribution consisting of inter-aggregate macropores and intra-aggregate micropores, with the transition from macro- to microporosity beginning at volumetric water content of $\approx 36 \%$ to $39 \%$. For inter-aggregate water contents that support optimal plant growth there is $45 \%$ change in water content that occurs over a relatively small matric suction range of $0-20 \mathrm{~cm} \mathrm{H}_{2} \mathrm{O}$ for $0.25-1-\mathrm{mm}$ and 0 to $-10 \mathrm{~cm} \mathrm{H}_{2} \mathrm{O}$ for 1-2-mm aggregate. Hysteresis is substantial between draining and wetting aggregate, which results in as much as a $\approx 10 \%$ to $20 \%$ difference in volumetric water content for a given matric potential. Hydraulic conductivity was approximately an order of magnitude higher for 1-2-mm than for 0.25-1-mm aggregate until significant drainage of the inter-aggregate pore space occurred. The large change in water content for a relatively small change in matric potential suggests that significant differences in water retention may be observed in microgravity as compared to earth.
\end{abstract}

Baked ceramic aggregates (fritted clay, arcillite) have been used in plant research for many years. Over 25 years ago, Van Bavel et al. (1978) noted "the material has a low dry bulk density, is non-cohesive, drains rapidly, retains a large quantity of plant available water, appears to be chemically inert and can easily be washed off the roots." Researchers have cited their use in vari-

Received for publication 8 Oct. 2004. Accepted for publication 6 Apr. 2005. The authors gratefully acknowledge Dr. Ted Tibbitts, Professor Emeritus, Univ. of Wisconsin, Madison, and Dr. Gary Stutte, Dynamac Corp., Kennedy Space Center, Fla., for reviewing previous versions of this manuscript. The authors acknowledge the assistance of Daniel Haddock, Universities Space Research Association, Houston, Tex., and Bill Mace, Dept. of Plants, Soils and Biometerology, Utah State Univ., Logan. This research was supported by NASA grant NAG9-1399, NASA's Advanced Life Support Program, and the Crew and Thermal Systems Division, Lyndon B. Johnson Space Center, Houston, Tex. ous studies ranging from plant carbon balance (McCree, 1983), nitrogen nutrition of loblolly pine (Pinus taeda L.) (Ludovici and Morris, 1996), cotton (Gossypium hirsutum L.) response to drought (Pace et al., 1999), to modeling water transport in the soil-plant continuum (Sperry et al., 1998).

In the last 10 years this material has become popular within the space flight community for both ground-based and microgravity plant experiments. Baked ceramic aggregate was found to be more "controllable, consistent and uniform" than peat moss based media (T.W. Tibbitts, personal communication). Variability in the physical and chemical properties of the components of peatmoss-based media was documented by Spomer et al. (1997). Baked ceramic aggregate can be sieved to a predetermined particle size distribution. Unlike peatmoss-based media, aggregate can 
be trickle irrigated to excess periodically during the day without loss of adequate aeration.

Baked ceramic aggregate was used in the development and testing of a microporous tube nutrient delivery system for microgravity (Morrow et al., 1993, 1994) and earth gravity (Tibbitts et al., 1995). Water transport through the microporous tube-aggregate-plant continuum was evaluated using 0.25-1-mm aggregate (Steinberg and Henninger, 1997). Baked ceramic aggregate has also been mixed with zeoponic media, another plant growth medium developed for space flight (Steinberg et al., 2000). The Wisconsin Center for Space Automation and Robotics has used 1-2-mm aggregate (Turface; Aimcor, Deerfield, Ill.) for their ongoing commercial plant research on the International Space Station (W. Zhou, personal communication). This same aggregate was also used in Photosynthesis Experiment System Testing and Operations which flew aboard the International Space Station in 2002 (Monje et al., 2001; Stutte et al., 2003). Levine (2002) has documented plans to use $1-2-\mathrm{mm}$ or $0.25-1-\mathrm{mm}$ aggregate in a future space flight.

Due to the widespread use of baked ceramic aggregates there is a need to establish more complete baseline physical and hydraulic characteristics of this material. This is especially important for space flight application since evidence suggests that bulk density, pore size distribution, and water transport properties change in microgravity (Jones and Or, 1999). Detailed characterization of ground-based properties of plant growth medium is absolutely essential for the interpretation of space flight data (Steinberg et al., 2002). Although some physical properties of these aggregates are available from the manufacturer, the only independent study of physical and hydraulic characteristics for this material was published over 25 years ago by Van Bavel et al. (1978). The purpose of this research is to provide a more detailed characterization of the physical properties and water relations characteristics of baked ceramic aggregates with particular focus on density and water transport conditions relevant to space flight.

\section{Materials and Methods}

BAKED CERAMiC AgGRegate. The commercial products Profile and Turface were used as sources of baked ceramic aggregate in this study. Both products are manufactured by Aimcor and differ only in particle size distribution. Turface was sieved to retain aggregates between 1 and $2 \mathrm{~mm}$ in diameter (hereafter referred to as 1-2-mm aggregate) using standard 1- and 2-mm sieves, a $50 \%$ loading rate, and a 15-min sieve time. Manufacturer specifications indicate that Profile contains aggregates between 0.25 and $1 \mathrm{~mm}$ in diameter. Profile was used "as is" and is referred to hereafter as $0.25-1-\mathrm{mm}$ aggregate. The particle size distributions of $0.25-1-\mathrm{mm}$ and $1-2-\mathrm{mm}$ aggregate were measured using standard sieve analysis (ASTM, 2003).

Compactibility. The maximum bulk density to which $0.25-1$ $\mathrm{mm}$ and 1-2-mm aggregate could be packed was determined using a number of different packing methods. These methods were evaluated for both dry and wet aggregate by packing material in a Plexiglass cylinder $(7.6 \mathrm{~cm}$ i.d.; $7.9 \mathrm{~cm}$ tall $)$. Several of the methods were also evaluated only for dry aggregate packed in square trays (15.2 cm side; $5 \mathrm{~cm}$ height) with and without $15.2-\mathrm{cm}-$ long microporous water delivery tubes (two tubes per tray) embedded in the aggregate. The square trays with microporous tubes resembled containers used for plant growth in space flight.

Dry packing tests in the cylinder were conducted using $\approx 100$ g oven-dried $\left(24 \mathrm{~h}\right.$ at $\left.105^{\circ} \mathrm{C}\right)$ aggregate and replicated 10 times.
Four packing methods were evaluated in addition to a control (no packing): Vibration. Aggregate was deposited in the cylinder, which was then shaken on a vibration table (frequency $60 \mathrm{~Hz}$; amplitude $0.33 \mathrm{~mm}$; model VP51D1; FMC Syntron, Homer City, Pa.) for $\approx 1$ min using a $750-$ g overburden $(7.6-\mathrm{cm}$ o.d. weight). This method is similar to ASTM standard D-4254 (ASTM, 2000). Tapping. Aggregate was deposited in the cylinder and an overburden of $350 \mathrm{~g}$ (7.6- cm o.d. weight) was placed on the surface to prevent particle bouncing and surface crowning. The side of the cylinder was tapped five times, rotated $90^{\circ}$ and the tapping process repeated. Rotation and tapping continued until settling ceased. Tamping. Aggregate was deposited in the cylinder in increments of $\approx 20 \mathrm{~g}$ yielding layers $\approx 1 \mathrm{~cm}$ in thickness. A glass stirring-rod was used to tamp (one to two tamps/second) through each layer after it was deposited. The surface was leveled for height measurement after tamping the final layer. This method has been commonly used for space flight application (G. Bingham and O. Monje, personal communication). Compaction. Aggregate was deposited in the cylinder in increments of $\approx 20 \mathrm{~g}$. After each layer was added to the cylinder, the surface was leveled by turning a solid plastic rod $(7.6 \mathrm{~cm}$ o.d., $2.3 \mathrm{~kg}$ ) a quarter-turn; it was then compacted (i.e., pushed) with the rod. This method is similar to that described by Klute (1986). Control. Aggregate was deposited in the cylinder and then leveled for height measurement. For all packing methods, four determinations of sample height were used to calculate sample volume. Sample mass (determined after oven drying) and volume were used to calculate bulk density.

Wet packing tests in the cylinder were conducted using aggregate brought to water contents of $0.2,0.4,0.6$, and $0.8 \mathrm{~g} \cdot \mathrm{g}^{-1}$. At each water content, three of the packing methods described above (vibration, tamping, and compaction) were evaluated in addition to a control (no packing), with each method replicated five times. Additionally, the mass of aggregate deposited in the cylinder was adjusted so that a total of $\approx 100 \mathrm{~g}$ of aggregate (drymass basis) was added. Packing procedures and bulk density calculations were identical to those described above for the dry packing tests.

Dry packing tests in the square trays were conducted using air-dry aggregate. Aggregate was in equilibrium with ambient air at a relative humidity of $\approx 60 \%$ to $70 \%$. In trays with and without porous tubes, packing methods of tapping and tamping were evaluated in addition to a control (no packing), with each method replicated three times. In all packing tests for the square trays, sufficient aggregate was added to achieve a final height of $3 \mathrm{~cm}$, equivalent to packing heights used in recent space flights (Monje et al., 2001). Aggregate was added all at once (control and tapping method) or in layers $\approx 1 \mathrm{~cm}$ in depth (tamping method). After adding aggregate to a tray, it was placed on a flat surface and rocked from side to side to spread the material. Procedures for the control and tamping method were similar to those used for the dry and wet packing tests in the cylinder. For the tamping method one to two tamps/second were made in 1-2- $\mathrm{cm}^{2}$ increments until the entire surface of the aggregate had been tamped. The tapping method differed in that an overburden of $784 \mathrm{~g}$ was used and each side of the tray was tapped with a rubber mallet until settling ceased. Sample height was taken as the mean of at least four measurements using a flat surface placed on the aggregate as the upper reference point. Sample mass (air-dry basis) and volume were used to calculate bulk density. Determining sample mass on an air-dry instead of oven-dry basis resulted in bulk density errors of $\approx 0.01 \mathrm{~g} \cdot \mathrm{cm}^{-3}$. 
Porosity. Total porosity was evaluated by calculation from measured particle density and bulk density and mercury intrusion porosimetry (Poremaster-60 porosimeter, Quantachrome Corp., Boynton Beach, Florida) (Danielson and Sutherland, 1986). Particle densities for $0.25-1$ and 1-2 mm aggregate were determined using the pycnometer method (Blake and Hartge, 1986).

Water AND AIR volumetric CONTENT. Volumetric water content or wettable porosity was determined from the volume of water contained within the total aggregate volume. It was also determined using magnetic resonance imaging (MRI) and nuclear magnetic resonance (NMR) relaxometry (Daidzic et al., 2003; Daidzic et al., 2004) using water as the infiltrating fluid. For MRI and most hydraulic measurements we were interested in the pore space that water penetrates under realistic dynamic flow (infiltration) and plant growth conditions. Saturation refers to that achievable under natural conditions (Hillel, 1998), without using special procedures such as flushing aggregate with $\mathrm{CO}_{2}$ or wetting under partial vacuum to remove entrapped air. Saturated volumetric water content $\left(\theta_{\mathrm{s}}\right)$ was obtained by quantifying the volume of water needed to slowly wet a known volume of aggregate to natural saturation. Volumetric air content or air filled porosity of saturated aggregate was calculated as the difference between total porosity and saturated water content (Hillel, 1998).

Water Retention. Water retention characteristics in the range of 0 to -20 or 0 to $-10 \mathrm{~cm} \mathrm{H}_{2} \mathrm{O}$ for $0.25-1-\mathrm{mm}$ or $1-2 \mathrm{~mm}$ aggregate, respectively, were measured with a hanging water column (Steinberg and Poritz, 2005). These measurements were performed for both wetting and drying media covered with a solid containment lid containing air/plant entry ports such as would be used in space flight. Water retention for drying aggregate was obtained for matric potentials of $-1,-4$, and $-8 \mathrm{~m}$ using a tempe cell, for matric potentials of $-15,-30$, and $-45 \mathrm{~m}$ using a pressure plate, and for matric potentials near -100 and $-400 \mathrm{~m}$ using thermocouple psychrometers (Dane and Hopmans, 2002). Water retention was also measured using the Haines method (Klute, 1986) for dry aggregate packed to the minimum and maximum densities. The air entry point was determined from analysis of the water retention relation and corresponds to the point at which an increase in suction causes water to be displaced by air (Hillel, 1998).

The measured water retention data were fitted to van Genuchten's parametric model that relates the volumetric water content $(\theta)$ to the matric suction $(h)$ :

$$
\Theta=\frac{\theta-\theta_{\mathrm{r}}}{\theta_{\mathrm{s}}-\theta_{\mathrm{r}}}=\left[\frac{1}{1+(\alpha|h|)^{n}}\right]^{m}
$$

where $\Theta$ is the relative water content or saturation, $\theta_{\mathrm{r}}$ and $\theta_{\mathrm{s}}$ are the residual and saturated water contents, respectively, and $\alpha, n$, and $m$ are parameters directly dependent on the shape of the $\theta(h)$ curve, with $m=1-1 / n$. The entire draining curve was fitted using multiple van Genuchten parameterized curves for inter-aggregate (macropore), intermediate and micropore retention data using the approach of Durner (1989) for dual porosity porous media. Wetting and draining water retention of the inter-aggregate pore space was fitted using measured values of $\theta_{\mathrm{s}}$ and $\theta_{\mathrm{r}}$ and fitted values of $\alpha$ and $n$ (0.25-1 mm aggregate: wetting, $\alpha=0.098$ $\mathrm{cm}^{-1}$ and $n=3.99$; draining, $\left.\alpha=0.062 \mathrm{~cm}^{-1}, n=10.28\right)(1-2-\mathrm{mm}$ aggregate: wetting, $\alpha=0.315 \mathrm{~cm}^{-1}$ and $n=4.37$; draining, $\alpha=$ $0.196 \mathrm{~cm}^{-1}$ and $n=5.6$ ).
Pore Size Distribution. The pore size corresponding to matric potentials of interest were calculated from the capillary equation assuming cylindrical capillaries:

$$
h=\frac{2 \gamma \cos \phi}{\rho g r}
$$

where $h$ is the hydraulic head, $\gamma$ is the surface tension of water, $\phi$ is the contact angle, $\rho$ is the density of water, $g$ is the acceleration of gravity and $r$ is the effective pore radius. Advancing and receding contact angles between water and baked ceramic aggregate of either particle size distribution, measured using the Washburn method (Bachman et al., 2000; Washburn, 1921), were confirmed to be zero.

Sphere-equivalent pore diameter was also calculated from NMR relaxation time (Kenyon, 1992). The specific surface and micropore volume of each of the two media were also determined from nitrogen $\left(\mathrm{N}_{2}\right)$ adsorption isotherms in conjunction with the Brunauer, Emmett, and Teller (BET) (Brunauer et al., 1938) equation using a Micromeritics Gemini V Series surface area analyzer (Micromeritics Instrument Corp., Norcross, Ga.).

GRAVITY DRAINED WATER CONTENT. Two depths of 0.25-1-mm and 1-2-mm aggregate were wet to saturation by drip irrigation and two alternative bottom-wetting methods to evaluate the effect of depth, air entrapment and the effect of particle containment lids on volumetric water content after gravity drainage. Gravity drainage was used as the reference water content because dripor top irrigated aggregate is often used for ground-based crop studies and will always be gravity drained. Measurements were made for two depths: $3 \mathrm{~cm}$, to minimize gravitational head as an earth based analogue to microgravity; and $6 \mathrm{~cm}$, analogous to earth based pot studies (Goins et al., 1997). Gravity drained water contents vary with aggregate depth due to a combination of gravitational head, soil water pressure, and air entrapment. Air-dry aggregate was packed to a density of 0.68 or $0.65 \mathrm{~g} \cdot \mathrm{cm}^{-3}$ for $0.25-1-\mathrm{mm}$ or $1-2-\mathrm{mm}$ particles, respectively, in $7.6-\mathrm{cm}$ i.d. cylinders containing a hydrophilic nylon membrane (pore size $\approx 200 \mu \mathrm{m}$ ) at the bottom. Three methods of wetting were used: 1) drip irrigation from the top with water dripping freely through the aggregate for $>20 \mathrm{~min}$; 2) aggregate with or without a porous polyvinyl chloride (PVC) lid resting on the surface was wetted up from the bottom by slowly raising the water level over a period of 1-2 h; and 3) aggregate wetted from the bottom by slowly raising the water level until it was above the surface of the aggregate. For method 3 air bubbles were physically removed by repeatedly inserting a narrow spatula into the medium, and aggregate was repacked to target depth.

For all wetting methods the volume of water in the aggregate was determined after allowing each treatment to drain until no further water was removed by gravity. This volume of water equaled the difference in mass between wet and air dried aggregate.

SATURATEd AND UnSATURATEd hydraulic CONDUCTIVITy. Saturated and unsaturated hydraulic conductivity were directly measured for $0.25-1-\mathrm{mm}$ and $1-2-\mathrm{mm}$ aggregate using the steady-state method with horizontal flow through shallow depths of progressively dryer aggregate as an earth based analog for space flight conditions (Steinberg and Poritz, 2005). Mualem's model (Mualem, 1976) was used to predict the unsaturated hydraulic conductivity function from the saturated conductivity and the draining portion of the water retention curve. Hydraulic conductivity $(\mathrm{K})$ was also estimated from permeability obtained from NMR relaxation time according to Sen at al. (1990) and 
Kenyon ( 1992). Hydraulic conductivity was calculated as (Hillel, 1998):

$$
K=k p \frac{g}{\eta}
$$

where $K$ is hydraulic conductivity $\left(\mathrm{cm} \cdot \mathrm{s}^{-1}\right), k$ is permeability $\left(\mathrm{cm}^{2}\right)$, $\rho$ is the density of water $\left(\mathrm{g}^{\circ} \mathrm{cm}^{-3}\right), g$ is the acceleration of gravity $\left(\mathrm{cm} \cdot \mathrm{s}^{-2}\right)$, and $\eta$ is the dynamic viscosity $\left(\mathrm{g} \cdot \mathrm{cm}^{-1} \cdot \mathrm{s}^{-1}\right)$.

\section{Results and Discussion}

An advantage of baked ceramic aggregates is that they can be sieved or combined to obtained specific particle size distributions. The particle size distribution of $0.25-1 \mathrm{~mm}$ differed from the manufacturer's specification of $0.25-1 \mathrm{~mm}$, with the majority of particles falling in the range of $0.5-1 \mathrm{~mm}$ (Fig. 1). There was no evidence of particle breakage during sieving that effected the cumulative particle size distribution.

All dry and wet packing methods evaluated in the cylinder increased bulk density in comparison with the unpacked control (Tables 1 and 2). For dry aggregate the maximum bulk densities obtained were $\approx 0.68$ and $0.64 \mathrm{~g} \cdot \mathrm{cm}^{-3}$ for $0.25-1$ (Table 1) and 1-2-mm (Table 2) particles, respectively, both with vibration or tapping. Packing at water contents of 0.2 or $0.4 \mathrm{~g} \cdot \mathrm{g}^{-1}$ resulted in significantly greater densities for some packing methods, but density decreased or remained unchanged for other packing methods. Thus packing with moist aggregate appears to offer no consistent advantage of increasing compatibility. At water contents $>0.4$ $\mathrm{g} \cdot \mathrm{g}^{-1}$ bulk density decreased for all packing methods.

Tapping and tamping aggregate contained in space flight sized $15.2 \times 15.2 \mathrm{~cm}$ trays to a depth of $3 \mathrm{~cm}$ produced similar bulk densities (Table 3 ) to those achieved in round cylinders (Tables 1 and 2). Both packing methods increased bulk density in comparison with the control (Table 3 ) and resulted in overall mean densities of $\approx 0.69$ and $0.65 \mathrm{~g} \cdot \mathrm{cm}^{-3}$ for $0.25-1-\mathrm{mm}$ and $1-2-\mathrm{mm}$ aggregate, respectively. Greater variation of density in the square tray is likely due to the shallow depth and much larger surface area than in the cylinder. Tapping and tamping methods of packing are a useful alternative to vibration in situations where a vibration table is unavailable or containers must be packed in-situ. The presence of two 15.2-cm-long microporous tubes, located within the aggregate, did not cause significant and repeatable changes in bulk density (Table 3 ). This indicates that imbedding

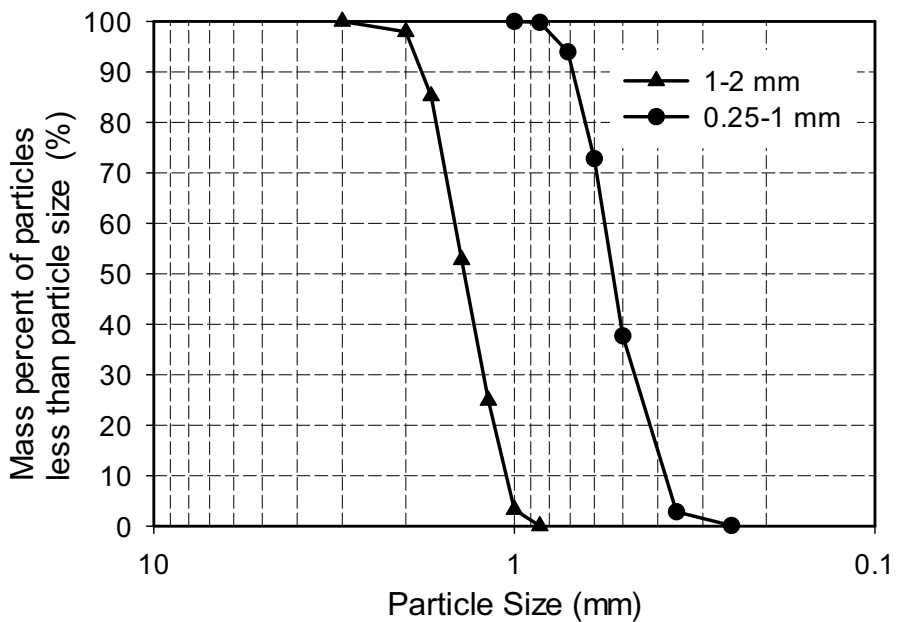

Fig. 1. Cumulative particle size distribution for $0.25-1-\mathrm{mm}$ and $1-2-\mathrm{mm}$ baked ceramic aggregate.
Table 1. Mean bulk densities for $0.25-1-\mathrm{mm}$ baked ceramic aggregate packed in a cylinder at water contents ranging from zero (oven dry) to $0.8 \mathrm{~g} \cdot \mathrm{g}^{-1}$. Packing methods included a control (no packing), tamping, compaction, tapping, and vibration.

Bulk densityz

\begin{tabular}{|c|c|c|c|c|c|}
\hline $\begin{array}{l}\text { Water } \\
\text { content }\end{array}$ & Control & Tamping & Compaction & Tapping & Vibration \\
\hline$\left(\mathrm{g} \cdot \mathrm{g}^{-1}\right)$ & --------- & & $--\left(\mathrm{g} \cdot \mathrm{cm}^{-3}\right)--$ & & 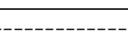 \\
\hline 0.0 & ${ }_{a} 0.614^{a}$ & $a_{a} 0.645^{b}$ & $0.633^{c}$ & $0.680^{\mathrm{d}}$ & ${ }_{a} 0.683^{d}$ \\
\hline 0.2 & $a^{a} 0.614 a$ & ${ }_{b} 0.654^{b}$ & ${ }_{b}^{\mathrm{a}} 0.650^{\mathrm{b}}$ & $---y$ & $0.687 \mathrm{c}$ \\
\hline 0.4 & ${ }_{b}^{a} 0.603^{a}$ & ${ }_{c} 0.634^{b}$ & ${ }_{b} 0.648^{b}$ & --- & ${ }_{b} 0.694 \mathrm{c}$ \\
\hline 0.6 & $0.489^{a}$ & $d^{0} 0.569^{b}$ & $0.616^{c}$ & --- & $0.576^{b}$ \\
\hline 0.8 & $0.508^{a}$ & --- & $0.618^{c}$ & --- & $d^{0.564 b}$ \\
\hline
\end{tabular}

${ }^{z}$ Mean separation in columns (subscripted letters) and in rows (superscripted letters) by Fisher's least significant difference test at $P \leq 0.05$.

yDashed lines indicate packing tests not performed.

Table 2. Mean bulk densities for 1-2-mm baked ceramic aggregate packed in cylinder at water contents ranging from zero (oven dry) to $0.6 \mathrm{~g} \cdot \mathrm{g}^{-1}$. Packing methods included a control (no packing), tamping, compaction, tapping, and vibration.

\begin{tabular}{|c|c|c|c|c|c|}
\hline \multirow{2}{*}{$\begin{array}{l}\text { Water } \\
\text { content }\end{array}$} & \multicolumn{5}{|c|}{ Bulk densityz } \\
\hline & Control & Tamping & Compaction & Tapping & Vibration \\
\hline$\left(\mathrm{g} \cdot \mathrm{g}^{-1}\right)$ & & & $--\left(\mathrm{g} \cdot \mathrm{cm}^{-3}\right)^{---}$ & & \\
\hline 0.0 & $a^{0.578^{a}}$ & $a^{0.616^{b}}$ & ${ }_{a} 0.602^{c}$ & $0.638^{\mathrm{d}}$ & $a^{0.639 d}$ \\
\hline 0.2 & ${ }_{\mathrm{ab}} 0.574^{\mathrm{a}}$ & ${ }_{b} 0.608^{b}$ & ${ }_{b} 0.614^{b}$ & ---y & $a^{0.643^{c}}$ \\
\hline 0.4 & ${ }_{\mathrm{b}} 0.569^{\mathrm{a}}$ & $\mathrm{c}^{0.597 \mathrm{~b}}$ & ${ }_{b} 0.608^{b}$ & --- & $a_{0} 0.643^{c}$ \\
\hline 0.6 & $c^{0.476^{\mathrm{a}}}$ & ${ }_{d} 0.558^{b}$ & $c^{0.586^{c}}$ & --- & ${ }_{b} 0.564^{b}$ \\
\hline
\end{tabular}

${ }^{\mathrm{z}}$ Mean separation in columns (subscripted letters) and in rows (superscripted letters) by Fisher's least significant difference test at $P \leq 0.05$.

yDashed lines indicate packing tests not performed.

Table 3. Mean bulk densities for 0.25-1-mm and 1-2-mm air-dry baked ceramic aggregate packed in square trays with and without imbedded microporous tubes. Packing methods included a control (no packing), tapping and tamping.

\begin{tabular}{llcl}
\hline & \multicolumn{3}{c}{ Bulk density } \\
\cline { 2 - 4 } Aggregate & Control & Tapping & Tamping \\
\hline 0.25-1 mm & & & \\
Without tubes & ${ }_{\mathrm{a}} 0.668^{\mathrm{a}}$ & ${ }_{\mathrm{a}} 0.693^{\mathrm{b}}$ & ${ }_{\mathrm{a}} 0.690^{\mathrm{b}}$ \\
$\begin{array}{l}\text { With tubes } \\
1-2 \mathrm{~mm}\end{array}$ & ${ }_{\mathrm{b}} 0.654^{\mathrm{a}}$ & ${ }_{\mathrm{a}} 0.689^{\mathrm{b}}$ & ${ }_{\mathrm{a}} 0.684^{\mathrm{b}}$ \\
Without tubes & & & \\
With tubes & ${ }_{\mathrm{a}} 0.613^{\mathrm{a}}$ & ${ }_{\mathrm{a}} 0.642^{\mathrm{b}}$ & ${ }_{\mathrm{a}} 0.648^{\mathrm{b}}$ \\
& ${ }_{\mathrm{a}} 0.617^{\mathrm{a}}$ & ${ }_{\mathrm{b}} 0.657^{\mathrm{b}}$ & ${ }_{\mathrm{b}} 0.650^{\mathrm{b}}$
\end{tabular}

zWithin aggregate type mean separation in columns (subscripted letters) and in rows (superscripted letters) by Fisher's least significant difference test at $P \leq 0.05$.

sensors or other objects in the aggregate has only a minor effect on bulk density.

Identification of methods for achieving maximum bulk density is critical for use of particulate plant growth media in microgravity. Even though lids or foams are used to contain particulates in root trays, movement or rearrangement of particles or clusters of particles within the tray may occur (Jones and Or, 1999; Reddi et al., 2005) resulting in a change in water retention and the continuity of hydraulic pathways within bulk aggregate.

Both particle size and density determine porosity, pore size distribution and thus water retention properties of the material. Mercury porosimetry yielded total porosities of $72.9 \%$ and $75.6 \%$ for $0.25-1-\mathrm{mm}$ and $1-2-\mathrm{mm}$ aggregate, respectively, 
Table 4. Maximum bulk density, particle density, surface area, total porosity, air filled porosity, saturated volumetric water content, interaggregate residual water content, and saturated hydraulic conductivity for $0.25-1-\mathrm{mm}$ and $1-2-\mathrm{mm}$ baked ceramic aggregate.

\begin{tabular}{lll}
\hline Parameter/property & $0.25-1 \mathrm{~mm}$ & $1-2 \mathrm{~mm}$ \\
\hline Bulk density $\left(\mathrm{g} \cdot \mathrm{cm}^{-3}\right)^{\mathrm{z}}$ & 0.68 & 0.64 \\
Particle density $\left(\mathrm{g} \cdot \mathrm{cm}^{-3}\right)$ & 2.5 & 2.5 \\
BET surface area $\left(\mathrm{m}^{2} \cdot \mathrm{g}^{-1}\right)$ & $83 \pm 0.75$ & $93.5 \pm 1$ \\
Total porosity $(\%)^{\mathrm{y}}$ & 72.8 & 74.4 \\
Air filled porosity $(\%)^{\mathrm{x}}$ & $\approx 8-9$ & $\approx 6-8$ \\
$\theta_{\mathrm{s}}\left(\mathrm{cm}^{3} \cdot \mathrm{cm}^{-3}\right)^{\mathrm{w}}$ & 0.65 & 0.665 \\
$\theta_{\mathrm{r}}\left(\mathrm{cm}^{3 \cdot} \mathrm{cm}^{-3}\right)^{\mathrm{v}}$ & 0.374 & 0.371 \\
Saturated hydraulic & & \\
$\quad$ conductivity $\left(\mathrm{cm} \cdot \mathrm{s}^{-1}\right)$ & $0.12 \pm 0.06$ & $0.941 \pm 0.5$
\end{tabular}

zOven dry basis.

yTotal porosity as calculated from 1- (bulk density/particle density).

Similar results also obtained by mercury porosimetry.

${ }^{x}$ Calculated from total porosity - saturated water content $\left(\theta_{\mathrm{s}}\right)$.

wSaturated water content $\left(\theta_{\mathrm{s}}\right)$.

${ }$ Residual water content for inter-aggregate pore space.
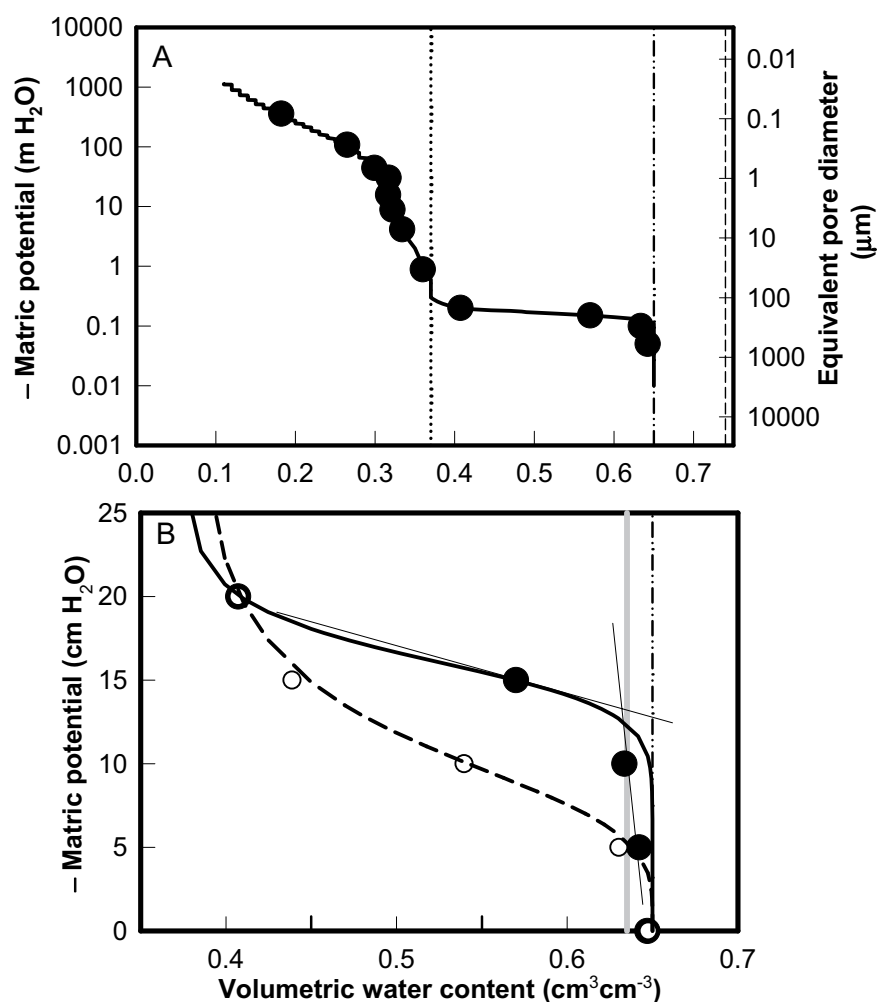

Fig. 2. Water retention characteristic for $0.25-1-\mathrm{mm}$ baked ceramic aggregate. (A) Complete draining curve $(\bullet$ measured, - fitted $)$. Residual reference water content for inter-aggregate pore space (...), total porosity (----), saturated water content $(-\bullet-)$. (B) Draining $(\bullet$, measured; - fitted) and wetting $(\mathrm{o}$, measured; ---, fitted) curves for inter-aggregate pore space. The air entry point (gray vertical line) was determined from analysis of the water retention relation and corresponds to the point at which an increase in suction causes water to be displaced by air (Hillel, 1998).

and were similar to those calculated from the bulk and particle density (Table 4). Saturated volumetric water contents (waterfilled porosity) were $0.65-0.67$ (65\% to $67 \%)$ for both particle size distributions, somewhat less than the total porosity (Table 4, Figs. 2A and 3A). MRI measurements yielded similar wettable porosities of $60 \%$ to $65 \%$ for $0.25-1-\mathrm{mm}$ or $1-2-\mathrm{mm}$ aggregate depending on the sample preparation. This resulted in an air filled
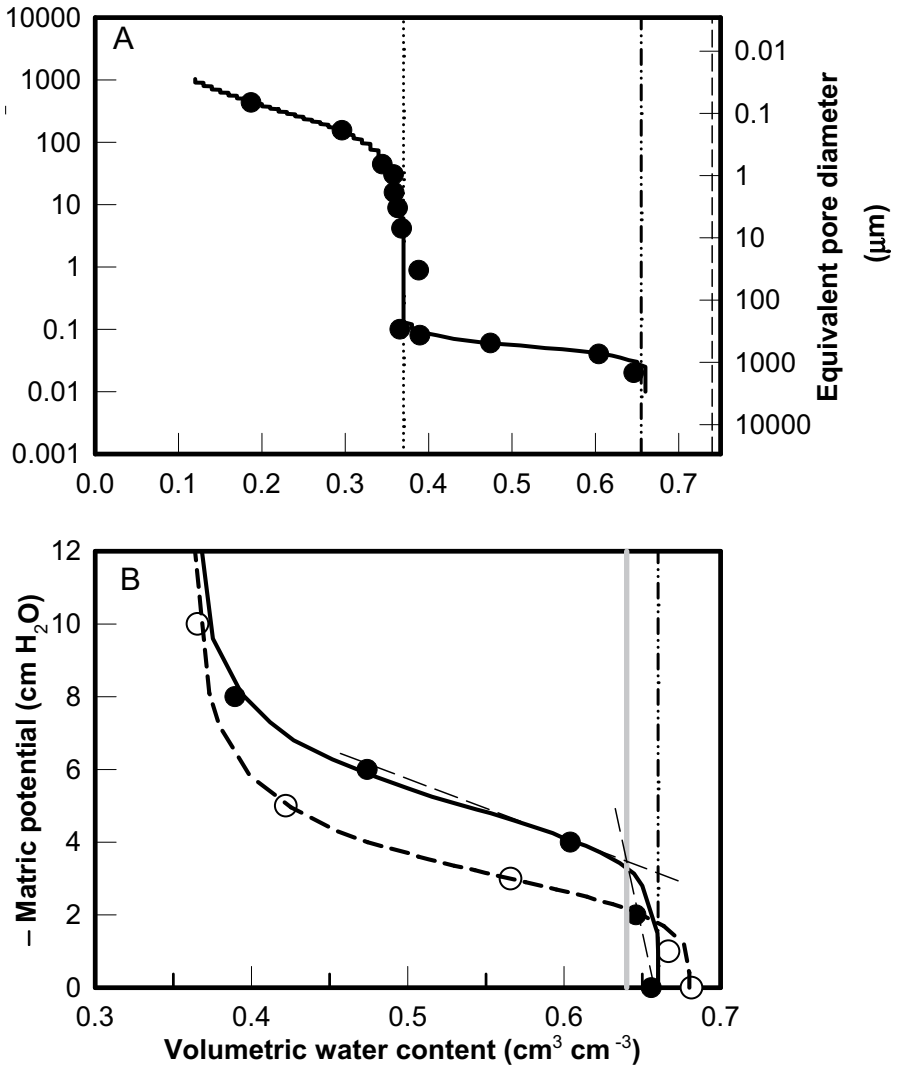

Fig. 3. Water retention characteristic for 1-2-mm-baked ceramic aggregate. (A) Complete draining curve $(\bullet$ measured, - fitted). Residual reference water content for inter-aggregate pore space (...), total porosity (----), saturated water content $(-\cdots-)$. (B) Draining $(\bullet$, measured; - fitted) and wetting (o, measured; ---, fitted) curves for inter-aggregate pore space. The air entry point (gray vertical line) was determined from analysis of the water retention relation and corresponds to the point at which an increase in suction causes water to be displaced by air (Hillel, 1998).

porosity at saturation of $8 \%$ to $9 \%$ and $6 \%$ to $8 \%$ for $0.25-1-\mathrm{mm}$ and 1-2-mm particles, respectively (Table 4).

The water retention characteristic from 0 to about $-1000 \mathrm{~m} \mathrm{H}_{2} \mathrm{O}$ shows a distinct bimodal pore size distribution for both $0.25-1$ $\mathrm{mm}$ (Fig. 2A) and 1-2-mm (Fig. 3A) aggregate corresponding to inter-aggregate and intra-aggregate pore space. The transition from inter- to intra-aggregate pore space occurs at water contents of $\approx 0.35-0.40$ and equivalent pore diameters of $\approx 100 \mu \mathrm{m}$.

Hysteresis between the wetting and draining curves was substantial, but more pronounced for $0.25-1 \mathrm{~mm}$ than for $1-2 \mathrm{~mm}$ aggregate (Figs. 2B and 3B). A stable reference for inter-aggregate water content determination (regardless of draining or wetting) was found for both $0.25-1-\mathrm{mm}$ and 1-2-mm aggregate, when saturated and then drained to a matric potential of $-20 \mathrm{~cm} \mathrm{H}_{2} \mathrm{O}$. Equilibrium water contents at $20 \mathrm{~cm} \mathrm{H}_{2} \mathrm{O}$ suction were 0.374 \pm 0.0062 and $0.371 \pm 0.0046$ and for $0.25-1-\mathrm{mm}$ and $1-2-\mathrm{mm}$ aggregate at dry bulk densities of 0.65 and 0.64 , respectively (Table 4). Using this reference as the residual water content for inter-aggregate pore space, the amount of water held within the inter- and intra-aggregate pore space of both media was $\approx 45$ and $55 \%$ of total wettable porosity (saturated volumetric water content), respectively.

Nuclear magnetic resonance relaxometry measurements showed two dominant and discrete relaxation times separated by two orders of magnitude, which also confirm a bi-modal pore size distribution for both media. Inter-aggregate sphere-equiva- 
lent pore diameters were in the range of 6-600 $\mu \mathrm{m}$ and $20-1200$ $\mu \mathrm{m}$ for $0.25-1-\mathrm{mm}$ and 1-2-mm aggregate, respectively, and agree well with the equivalent pore diameters calculated from the capillary equation (Figs. 2A and 3A). Intra-aggregate pores were in the range of $\approx 100-6000 \mathrm{~nm}(0.1-6 \mu \mathrm{m})$ for both particle size distributions (data not shown). There was no measurable pore volume less than $10 \mathrm{~nm}$. For both media $\approx 62 \%$ to $63 \%$ of wettable MRI porosity is contained in the inter-aggregate pores while $\approx 37 \%$ to $38 \%$ is contained within the intra-aggregate pores (data not shown). These differ from those obtained from the water retention relation due to the choice of water content (and pore size) for the transition between inter- and intra-aggregate pore spaces. In general, however, inter-particular and intra-particular pore size measured by MRI and calculated from the capillary equation (Figs. 2A and 3A) were in reasonable agreement.

Plant transpiration declines and wilting occurs for both high (Steinberg and Henninger, 1997) and low light (S. Steinberg, personal communication) conditions when inter-aggregate pores of 0.25-1-mm aggregate are drained. For both media drainage of the inter-aggregate pore space that supports optimal plant growth results in a $\approx 45 \%$ decrease in volumetric water content that occurs over a relatively small matric suction range of 0 to -10 or $-20 \mathrm{~cm} \mathrm{H}_{2} \mathrm{O}$ for $1-2-\mathrm{mm}$ and $0.25-1-\mathrm{mm}$ aggregate, respectively (Figs. 2B and 3B). Data in Fig. 2B shows that most of the water in the inter-aggregate space of $0.25-1-\mathrm{mm}$ aggregate is released between -8 and $-20 \mathrm{~cm} \mathrm{H}_{2} \mathrm{O}$, which corresponds to equivalent pore diameters ranging from $\approx 400-150 \mu \mathrm{m}$. For $1-2$-mm aggregate a significant amount of water is released from -4 to $-6 \mathrm{~cm} \mathrm{H}_{2} \mathrm{O}$, corresponding to equivalent pore diameters of $\approx 750-500 \mu \mathrm{m}$ (Fig. 3B). The effect of bulk density on desorption of the inter-aggregate pores space was evaluated for the minimum and maximum air-dry densities observed in this study (Fig. 4). Variation in bulk density has a greater impact on water desorption of $0.25-1-\mathrm{mm}$ than 1-2-mm aggregate, especially near saturation.

For draining aggregate air entry occurs at volumetric water contents $\approx 0.01 \mathrm{~cm}^{3} \cdot \mathrm{cm}^{-3}(1.5 \%)$ below saturation (Figs. $2 \mathrm{~B}$ and $3 \mathrm{~B}$ ), which corresponds to a matric potential about -10 to -15 or -3 to $-4 \mathrm{~cm} \mathrm{H}_{2} \mathrm{O}$ for $0.25-1-\mathrm{mm}$ or 1-2-mm aggregate, respectively. Due to hysteresis in the water retention relation, water content can vary by $\approx 0.15$ or $0.10 \mathrm{~cm}^{3} \cdot \mathrm{cm}^{-3}(15 \%$ to $20 \%)$ between wetting and draining $0.25-1-\mathrm{mm}$ and $1-2-\mathrm{mm}$ aggregate, respectively, at a matric potential corresponding to the air entry point in draining aggregate.

Space flight experiments with similar particle sizes have controlled matric potential to at or wetter than the air entry point [1-2-mm aggregate, $-3 \mathrm{~cm} \mathrm{H}_{2} \mathrm{O}$; (Monje et al., 2001)] [(0.6-1mm zeoponic medium; $-5 \mathrm{~cm} \mathrm{H}_{2} \mathrm{O}$; (Morrow et al., 1995)]. In the latter experiment elevated alcohol dehydrogenase activity, believed to be an indicator of hypoxic conditions in plants, was found in roots from space flight (Porterfield et al., 2000). This result was attributed to displacement of air-filled porosity by water in microgravity, and root modules, sealed to contain particulates, that limited oxygen exchange (Porterfield et al., 2000). Using a matric potential control point wetter than the air entry point may by itself lead to aeration problems in microgravity where there is no stratification of air and water, although the ground-based control may appear to have adequate aeration depending on the depth of the matric potential control sensor in the medium.

On earth these media are often drip irrigated from the top to excess and allowed to drain periodically during each day (Spomer et al., 1997). This method of watering also serves as an alternative baseline condition that simulates space flight conditions for crop
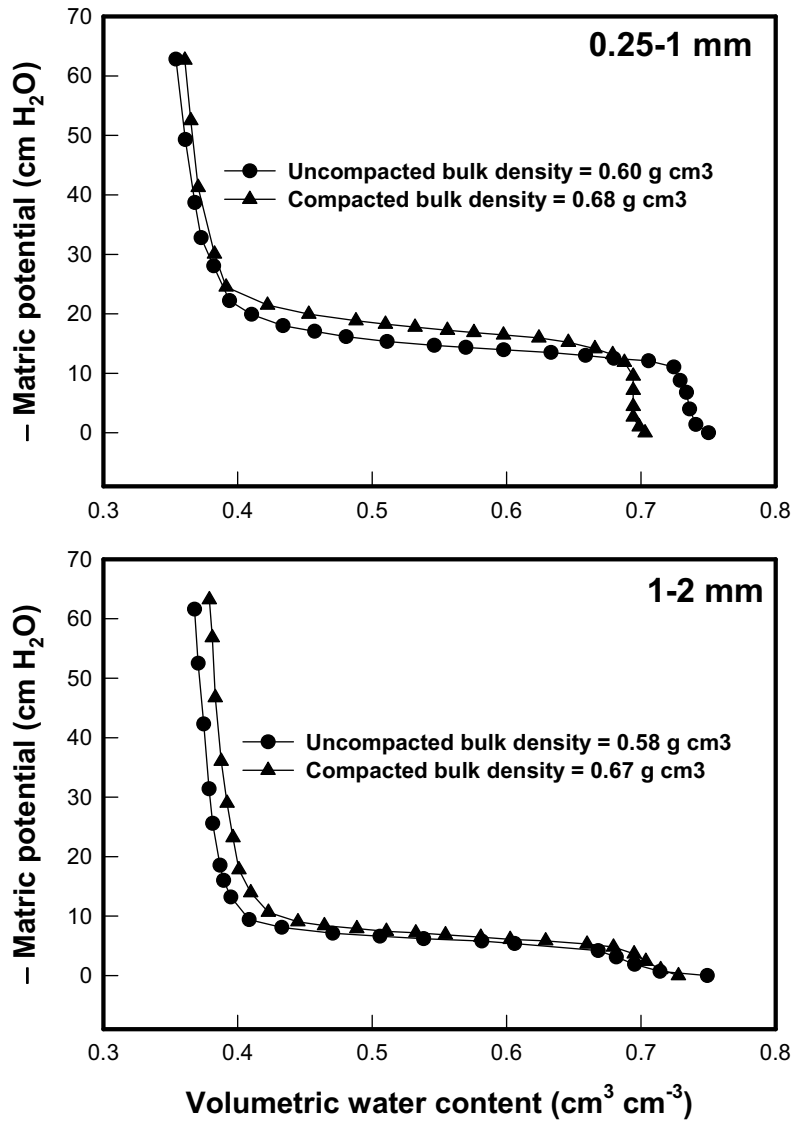

Fig. 4. Water retention characteristic of $0.25-1-\mathrm{mm}$ and $1-2-\mathrm{mm}$ baked ceramic aggregate with and without compaction to maximum dry bulk density.

testing when space flight systems are unavailable (Goins et al., 1997; Wheeler, 2002). The water content after gravity drainage of both $0.25-1-\mathrm{mm}$ and $1-2-\mathrm{mm}$ particles ranged from 0.54 to 0.74 depending on wetting method and aggregate depth (Table 5). The highest gravity drained water contents of $0.71-0.74$ were obtained when entrapped air was physically removed from saturated aggregate prior to gravity drainage (Table 5). Gravity drained water contents of 0.61 or 0.55 , obtained from drip irrigation of $6 \mathrm{~cm}$ deep aggregate, correspond to matric potentials of about -15 or $-5 \mathrm{~cm} \mathrm{H}_{2} \mathrm{O}$ for $0.25-1-\mathrm{mm}$ or $1-2-\mathrm{mm}$ aggregate, respectively (Figs. 2B and 3B). For both media gravity drained water content is somewhat drier than the water content of $\approx 0.64$ for draining aggregate obtained with matric potential control at $-5 \mathrm{~cm} \mathrm{H}_{2} \mathrm{O}$ [depth not given, 0.6-1 mm zeoponic medium (Morrow et al., 1995)] or $-3 \mathrm{~cm} \mathrm{H}_{2} \mathrm{O}$ [3 cm depth, 1-2-mm aggregate (Monje et al., 2001; Stutte et al., 2003)], respectively. This result indicates that use of gravity drained conditions to simulate that of space flight should be done with caution. The lowest gravity drained water contents of $<0.6$ were obtained by slowly wetting aggregate from the bottom while the top of the material was covered with a particle containment lid, such as would be required for space flight (Table 5). The particle containment lids in contact with the aggregate may have allowed for the development of moisture films that limited air transport out of the substrate. Particle containment lids limiting air transport in plant growth media has been eluded to previously (Porterfield et al., 2000).

The dual porosity of this material may contribute to air entrapment. From Eq. [2] it can be seen that the water pressure required to wet an inter-aggregate pore is less than for the intra-aggregate 
Table 5. Volumetric water contents of $0.25-1-\mathrm{mm}$ and 1-2-mm baked ceramic aggregate following gravity drainage from a saturated condition. Methods used to achieve saturation included wetting from the top of the container with free drainage (drip irrigation), wetting from the bottom (bottom), wetting from the bottom and removing air (air removal), and wetting from bottom with porous lid on sample (bottom w/lid). Wetting from the bottom was accomplished by raising the water table.

\begin{tabular}{lccccc}
\hline & \multicolumn{2}{c}{$\begin{array}{c}0.25-1-\mathrm{mm} \text { aggregate } \\
\text { (mean } \pm \mathrm{SD})\end{array}$} & & \multicolumn{2}{c}{$\begin{array}{c}\text { 1-2-mm aggregate } \\
(\text { mean } \pm \mathrm{SD})\end{array}$} \\
\cline { 2 - 3 } \cline { 5 - 6 } Wetting method & \multicolumn{2}{c}{$3 \mathrm{~cm} \mathrm{depth}$} & $6 \mathrm{~cm}$ depth & & \multicolumn{2}{c}{$3 \mathrm{~cm} \mathrm{depth}$} & $6 \mathrm{~cm}$ depth \\
\cline { 2 - 3 } Drip irrigation & $0.66 \pm 0.005^{\mathrm{z}}$ & $0.61 \pm 0.007$ & & $0.6 \pm 0.007$ & $0.55 \pm 0.0004$ \\
Air removal & $0.75 \pm 0.003$ & $0.74 \pm 0.020$ & & $0.71 \pm 0.030$ & $0.62 \pm 0.010$ \\
Bottom & $0.67 \pm 0.008$ & $0.62 \pm 0.002$ & & $0.61 \pm 0.018$ & $0.58 \pm 0.006$ \\
Bottom w/lid & $0.58 \pm 0.010$ & $0.57 \pm 0.007$ & & $0.57 \pm 0.010$ & $0.54 \pm 0.007$
\end{tabular}

zThree replicates.

pores. Water infiltrating through dry aggregate will rapidly fill the larger pores. Thus air escaping from the slower filling intraaggregate pores may become trapped by the already water filled inter-aggregate pores. This phenomenon accompanied by the dominance of capillary forces and the slow and incomplete displacement of air from macropores, due to the lack of buoyancy, could become a serious air entrapment problem in microgravity conditions.

The range of hydraulic conductivity for the inter-aggregate pore space of $0.25-1-\mathrm{mm}$ and $1-2-\mathrm{mm}$ aggregate measured by the steady-state method and predicted by the Mualem/van Genuchten models (Mualem, 1976; van Genuchten, 1980) is shown in Fig. 5. Saturated hydraulic conductivity determined for $1-2 \mathrm{~mm}$ aggregate was $\approx 0.9 \mathrm{~cm} \cdot \mathrm{s}^{-1}$, nearly 1 order of magnitude greater than $\approx 0.12 \mathrm{~cm} \cdot \mathrm{s}^{-1}$ for $0.25-1-\mathrm{mm}$ (Table 4 ) and (Steinberg and Poritz, 2005). MRI measurements of saturated hydraulic conductivity were reasonably similar to those listed in Table 4 and shown in Fig. 5. For saturated 0.25-1-mm aggregate the permeability and hydraulic conductivity were $163 \mu \mathrm{m}^{2}$ and $0.163 \mathrm{~cm} \cdot \mathrm{s}^{-1}$, respectively; for saturated $1-2-\mathrm{mm}$ aggregate the permeability and hydraulic conductivity were $724 \mu \mathrm{m}^{2}$ and 0.724 $\mathrm{cm} \cdot \mathrm{s}^{-1}$, respectively.

The unsaturated hydraulic conductivity as a function of volumetric water content of 1-2-mm aggregate remains about 1 order of magnitude greater than that of $0.25-1-\mathrm{mm}$ aggregate until the inter-aggregate pores drain at a water content of $\approx 0.40$ (Fig. 5). The water content at which hydraulic conductivity becomes limit- ing to plant transpiration depends environmental conditions. As mentioned earlier, for $0.25-1-\mathrm{mm}$ and 1-2-mm baked ceramic aggregate this generally occurs when a substantial portion of the inter-aggregate pores have drained and hydraulic conductivity has fallen by $2-3$ orders of magnitude to $\approx 1 \times 10^{-3} \mathrm{~cm} \cdot \mathrm{s}^{-1}$. Both media have stable inter-aggregate reference water contents near 0.4 , thus it is not surprising that both media have a similar hydraulic conductivity at a water content of $\approx 0.40$. Once the inter-aggregate pores drain the remaining water is held in the intra-aggregate pores, which are similar in size for both media. MRI measurements of $0.25-1-\mathrm{mm}$ aggregate with drained inter-aggregate pores resulted in permeability of $78 \mu^{2}$ and effective hydraulic conductivity of $\approx 7.8 \times 10^{-5} \mathrm{~cm} \cdot \mathrm{s}^{-1}$ for a pore size of $\approx 6 \mu \mathrm{m}$.

When viewed on a matric potential basis (Fig. 5) the unsaturated hydraulic conductivity of $0.25-1-\mathrm{mm}$ or $1-2-\mathrm{mm}$ aggregate remained at near saturated values until about -15 or $-3 \mathrm{~cm} \mathrm{H}_{2} \mathrm{O}$, the approximate air entry point for each particle size distribution, respectively. Thereafter unsaturated hydraulic conductivity declined rapidly with small changes in matric potential. Due to hysteresis in the water retention relation (Figs. 2B and 3B), use of matric potential to control aggregate water content could result in variability in unsaturated hydraulic conductivity within the aggregate, depending on control set points and whether the media is wetting or draining.

Previous research has shown that plants grown in baked ceramic aggregate exhibited wilting and reduced transpiration rates when the inter-aggregate pores are drained; and that $70 \%$ of water extractable by plants has been depleted at the interaggregate residual water content (Steinberg and Henninger, 1997). Thus, of the total amount of water held in the media $\approx 45 \%$ supports optimal plant growth, while $\approx 55 \%$ is held in the intra- aggregate pores, and is not easily available to plants. For the particle sizes studied here, the large changes in water content over a relatively narrow matric potential range suggests that significant differences in water retention and distribution may be observed in microgravity compared to observations made on Earth. This difference increases with media depth. Furthermore, air entrapment is significant in small volumes of aggregate, especially with the lack of headspace above the material when a
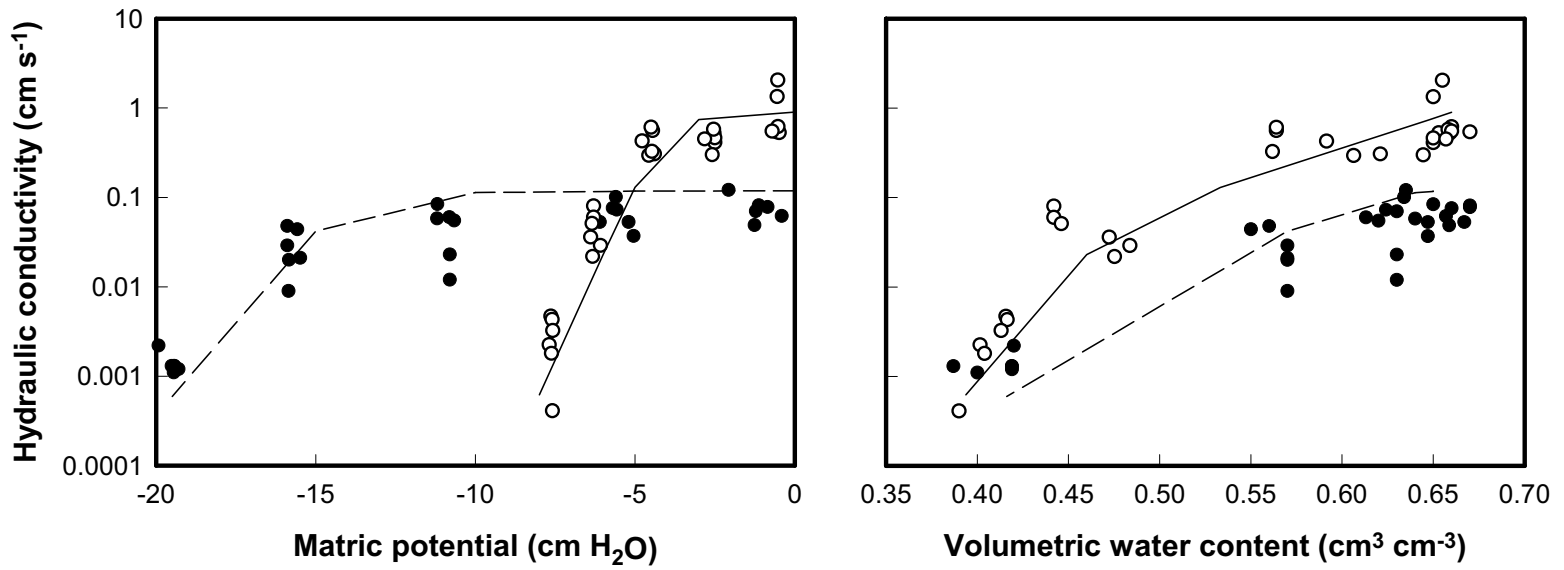

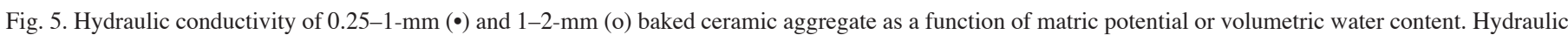

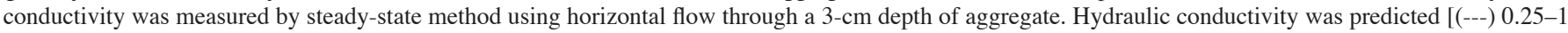
$\mathrm{mm}$; (-) 1-2 mm] using the Van Genutchen/Mualem models. 
particle containment lid is present. Detailed characterization of growth medium physical and hydraulic properties is necessary to interpret microgravity data and separate environmental from microgravity effects on plant growth during space flight. Careful attention to operational detail would be required to attempt to mimic space flight conditions for baseline studies on earth and would be limited to shallow media thicknesses, which degrade the representative nature of the sample.

\section{Literature Cited}

American Society for Testing and Materials. 2000. Standard test methods for minimum index density and unit weight of soils and calculation of relative density. Amer. Soc. Testing and Materials D 4254-00. ASTM, East Conshohocken, Pa.

American Society for Testing and Materials. 2003. Standard test method for particle-size analysis of soils. Annual book of ASTM D 3404-91. Amer. Soc. Testing and Materials, East Conshohocken, Pa.

Bachman, J., R. Horton, R.R. van der Ploeg, and S. Woche. 2000. Modified sessile drop method for assessing initial soil water contact angle of sandy soil. Soil Sci. Soc. Amer. J. 64:564-567.

Blake, G.R. and K.H. Hartge. 1986. Particle density. p. 377-381. Methods of soil analysis Part I: Physical and mineralogical methods. ASA, SSSA, CSSA, Madison, Wis.

Brunauer, S., P.H. Emmett, and E. Teller. 1938. Adsorption of gases in multimolecular layers. J. Amer. Chem. Soc. 60:309-319.

Daidzic, N.E., P. Fantazzini, S. Altobelli, E. Schmidt, and J.I.D. Alexander. 2004. Pore-size distribution and porosity measurements in soil porous media by MRI, p. 362-367. In: R. Malla and A. Maji (eds.). Earth and space 2004. Engineering, construction, and operations in challenging environments. Amer. Soc. Civil Eng., Reston, Va.

Daidzic, N.E., S. Altobelli, A. Caprihan, E. Schmidt, and J.I.D. Alexander. 2003. Estimate of porosity length-scales in soils by MRI for microgravity plant growth experiments. J. Magnetic Resonance Imaging (Spec. Iss.) 21:421-450.

Dane, J.H. and J.W. Hopmans. 2002. Water retention and storage, p. 671-675. In: J.H. Dane and G.C. Topp (eds.). Methods of soils analysis: Part 4. Physical methods. SSSA, Madison, Wis.

Danielson, R. E. and P. L. Sutherland. 1986. Porosity, p. 443-461. In: A. Klute (ed.). Methods of soil analysis: Part 1. Physical and mineralogical methods. ASA, SSSA, Madison, Wis.

Durner, W. 1989. Predicting the unsaturated hydraulic conductivity using multi-porosity water retention curves, p. 185-202. In: F.J.L.M. Th. van Genuchten and L.J. Lund (eds.). Proc. Intl. Wkshp. on indirect methods for estimating the hydraulic properties of unsaturated soils. 11-13 Oct. 1989. Univ. of California, Riverside.

Goins, G.D., H.G. Levine, C.L. Mackowiak, R.M. Wheeler, J.D. Carr, and D.W. Ming. 1997. Comparison studies of candidate nutrient delivery systems for plant cultivation in space. Soc. Automotive Eng. Tech. Paper 972304. SAE, Warrendale, Pa.

Hillel, D. 1998. Environmental Soil Physics. Academic, New York.

Jones, S.B. and D. Or. 1999. Microgravity effects on water flow and distribution in unsaturated porous media: Analysis of flight experiments. Water Resources Res. 35:929-942.

Kenyon, W.E. 1992. Nuclear magnetic resonance as a petrophysical measurement. Nuclear Geophysics 6:152-171.

Klute, A. 1986. Water retention: Laboratory methods, p. 635-662. In: A Klute (ed.). Methods of soil analysis: Part 1, Physical and mineralogical methods. ASS, SSSA, CSSA, Madison, Wis.

Levine, H. 2002. Water offset nutrient delivery experiment (Wonder). Annu. Rpt. Dynamac Corp., Kennedy Space Center, Fla.

Ludovici, K.H. and L.A. Morris. 1996. Responses of loblolly pine, sweetgum and crab grass roots to localized increases in nitrogen in two watering regimes. Tree Physiol. 16:933-939.

McCree, K.J. 1983. Carbon balance as a function of plant size in sorghum plants. Crop Sci. 23:1173-1177.
Monje, O., G.W. Stutte, H.T. Wang, and C.J. Kelly. 2001. NDS water pressures affect growth rates by changing leaf area, not single leaf photosynthesis. Soc. Automotive Eng. Tech. Paper 2002-01-2277. SAE, Warrendale, Pa.

Morrow, R.C., R.J. Bula, T.W. Tibbitts, and W.R. Dinauer. 1994. The Astroculture flight experiment series, validating technologies for growing plants in space. Adv. Space Res. 14:29-37.

Morrow, R.C., W.R. Dinauer, R.J. Bula, and T.W. Tibbitts. 1993. The ASTROCULTURE-1 flight experiment: Pressure control of the WCSAR porous tube nutrient delivery system. Soc. Automotive Eng. Tech. Paper 932282. SAE, Warrendale, Pa.

Morrow, R.C., N.A. Duffie, T.W. Tibbitts, R.J. Bula, D.W. Ming, D.J. Barta, R.M. Wheeler, and D.M. Porterfield. 1995. Plant response in the ASTROCULTURE flight experiment unit. Soc. Automotive Eng. Tech. Paper 951624. SAE, Warrendale, Pa.

Mualem, Y. 1976. A new model for predicting the hydraulic conductivity of unsaturated porous media. Water Resources Res. 12:513-522.

Pace, P.F., H.T. Cralle, S.H.M. El-Halawany, J.T. Cothren, and S.A. Sensemean. 1999. Drought-induced changes in shoot and root growth of young cotton plants. J. Cotton Sci. 3:183-187.

Porterfield, D.M., D.J. Barta, D.W. Ming, R.C. Morrow, and M.E. Musgrave. 2000. Astroculture root metabolism and cytochemical analysis. Adv. Space Res. 26:315-318.

Reddi, L.R., M. Xiao, and S.L. Steinberg. 2005. Discontinuous pore fluid distribution under micorgravity-KC-135 flight investigations. Soil Sci. Soc. Amer. J. 69:593-598.

Sen, P. N., C. Straley, W. E. Kenyon, and M.S. Wittingham. 1990. Surface-to-volume ratio, charge density, nuclear magnetic relaxation, and permeability in clay-bearing sandstones. Geophysics 55:61-69.

Sperry, J.S., F.R. Adler, G.S. Campbell, and J.P. Comstock. 1998. Limitation of plant water use by rhizosphere and xylem conductance: results from a model. Plant Cell Environ. 21:347-359.

Spomer, L.A., W.L. Berry, and T.W. Tibbitts. 1997. Plant culture in solid media, p. 105-118. In: R.W. Langhans and T.W. Tibbitts (eds.). Plant growth chamber handbook. Iowa State Univ. Press, Ames.

Steinberg, S.L., D.W. Ming, and D. Henninger. 2002. Plant production systems for microgravity: critical issues in water, air and solute transport through unsaturated porous media. NASA/Tech. Memo2002-210774. Natl. Aeronautics \& Space Admin./Johnson Space Ctr., Houston.

Steinberg, S.L. and D. Poritz. 2005. Measurement of hydraulic characteristics of porous media used to grow plants in microgravity. Soil Sci. Soc. Amer. J. 69:301-310.

Steinberg, S.L. and D.L. Henninger. 1997. Response of the water status of soybean to changes in soil water potentials controlled by the water pressure in microporous tubes. Plant Cell Environ. 20:1506-1516.

Steinberg, S.L., D.W. Ming, K.E. Henderson, C. Carrier, J.E. Gruener, D.J. Barta, and D.L. Henninger. 2000. Wheat response to differences in water and nutritional status between zeoponic and hydroponic growth systems. Agron. J. 92:353-360.

Stutte, G.W., O. Monje, and S. Anderson. 2003. Wheat (Triticum aesativum I. cv. USU Apogee) growth onboard the International Space Station (ISS): Germination and early development. Plant Growth Regulat. Soc. Amer. 30:66-71.

Tibbitts, T.W., W. Cao, and T. Frank. 1995. Development of a siphon system with porous tubes for maintaining a constant negative water pressure in a rooting matrix. Biotronics 24:7-14.

Van Bavel, C.H.M., R. Lascano, and D.R. Wilson. 1978. Water relations of fritted clay. Soil Sci. Soc. Amer. J. 42:657-659.

van Genuchten, M. Th. 1980. A closed-form equation for predicting the hydraulic conductivity of unsaturated soils. Soil Sci. Soc. Amer. J. 44:892-898.

Washburn, E.W. 1921. The dynamics of capillary flow. Physical Rev. 17:273-283.

Wheeler, R. 2002. ALS crop list and baseline environment for ISS. NASA Biol. Sci. Office, Kennedy Space Center, Fla. 